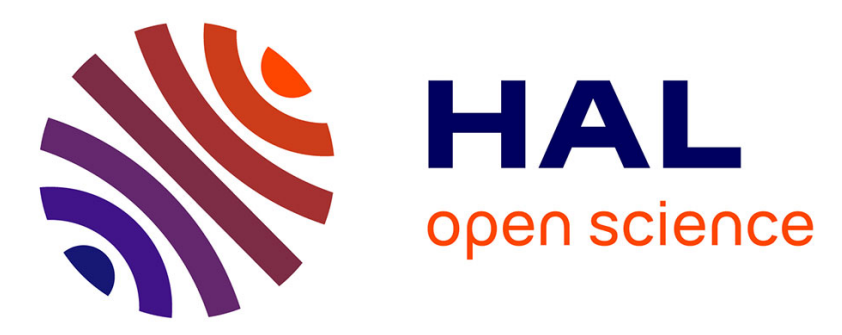

\title{
Enhanced aminolysis of cyclic carbonates by $\beta$-hydroxylamines for the production of fully biobased polyhydroxyurethanes
}

\author{
Baptiste Quienne, Rinaldo Poli, Julien Pinaud, Sylvain Caillol
}

\section{To cite this version:}

Baptiste Quienne, Rinaldo Poli, Julien Pinaud, Sylvain Caillol. Enhanced aminolysis of cyclic carbonates by $\beta$-hydroxylamines for the production of fully biobased polyhydroxyurethanes. Green Chemistry, 2021, 23 (4), pp.1678-1690. 10.1039/D0GC04120C . hal-03148901

\author{
HAL Id: hal-03148901 \\ https://hal.science/hal-03148901
}

Submitted on 22 Feb 2021

HAL is a multi-disciplinary open access archive for the deposit and dissemination of scientific research documents, whether they are published or not. The documents may come from teaching and research institutions in France or abroad, or from public or private research centers.
L'archive ouverte pluridisciplinaire HAL, est destinée au dépôt et à la diffusion de documents scientifiques de niveau recherche, publiés ou non, émanant des établissements d'enseignement et de recherche français ou étrangers, des laboratoires publics ou privés. 


\section{Enhanced aminolysis of cyclic carbonates by $\beta$-hydroxylamines for the production of fully biobased polyhydroxyurethanes}

Baptiste Quienne ${ }^{\mathrm{a}}$, Rinaldo Poli ${ }^{\mathrm{b},}{ }^{,}$, Julien Pinauda, Sylvain Caillol ${ }^{\mathrm{a},{ }^{*}}$

aCGM, Univ Montpellier, CNRS, ENSCM, Montpellier, France

${ }^{\text {b} C N R S, ~ L C C ~(L a b o r a t o i r e ~ d e ~ C h i m i e ~ d e ~ C o o r d i n a t i o n), ~ U n i v e r s i t e ́ ~ d e ~ T o u l o u s e, ~ U P S, ~ I N P T, ~} 205$ Route de Narbonne, BP 44099, F-31077, Toulouse Cedex 4, France

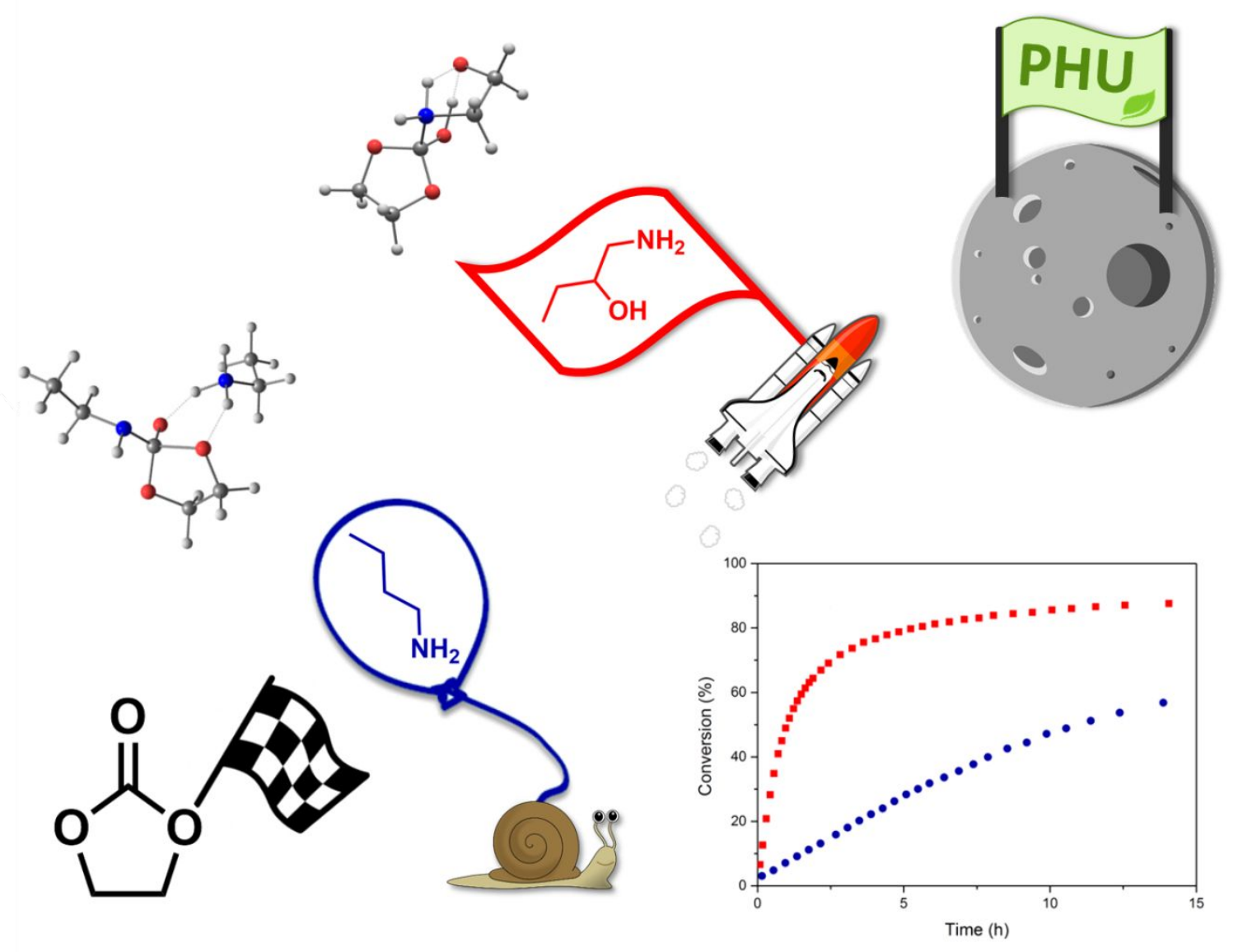

\section{Abstract}

The aminolysis of five-membered cyclic carbonates which results in polyhydroxyurethanes (PHUs) is one of the most promising synthetic pathway to achieve isocyanate-free polyurethanes (NIPUs), one of the main industrial challenges over the coming years. This study highlighted the higher reactivity of $\beta$-hydroxylamines toward cyclic carbonate in comparison to classical alkylamines through the determination of their reaction rate constants. The key role of the $\beta-\mathrm{OH}$ substituent in the aminolysis was enlighten by a DFT investigation. Polyfunctional alkylamine and $\beta$-hydroxylamine were then used for the synthesis of fully biobased PHU thermosets. The higher reactivity of $\beta$-hydroxylamines was 
confirmed by the gelation time gap between the two formulations studied. After curing, the thermal and thermo-mechanical properties of the thermosets were compared.

\section{Keywords}

DFT; reactivity; $\beta$-hydroxylamines; cyclic carbonate; polyhydroxyurethanes; biobased polymers;

\section{Introduction}

Polyurethanes (PUs), ranking $6^{\text {th }}$ among all polymers based on annual worldwide production, are commonplace in everyday life as foams, coatings, adhesives, elastomers, insulation, composites, and so forth. ${ }^{1-3}$ They are present in a wide range of applications due to the numerous industrially available polyols, which allow to cover a large panel of properties. ${ }^{4,5}$ However, their synthesis requires the use of isocyanates, known to be harmful for human health and for the environment. ${ }^{6,7}$ In order to limit the use of isocyanates, the development of isocyanate-free PUs has emerged over the last decade and has gained increasing attention in both the academic and industrial communities. ${ }^{8-10}$ Hence, the aminolysis of 5-membered cyclic carbonates, which yields polyhydroxyurethanes (PHUs), is nowadays the most promising and described route to non-isocyanate polyurethanes (NIPUs). ${ }^{11-14}$ This route has the advantage that these carbonates are easily obtained by the carbonation of commercial epoxides. Moreover, this route valorizes $\mathrm{CO}_{2}$ as a cheap, renewable and non-toxic resource, which makes this pathway the least toxic and most eco-friendly route to NIPU and PHUs. ${ }^{15-17}$ Indeed, larger ring size cyclic carbonates require the use of toxic agents such as phosgene or cyclic chloroformates for their synthesis. ${ }^{18,19}$

However, five-membered cyclic carbonates suffer from lower reactivity compared to isocyanates or larger cyclic carbonates. ${ }^{20,21}$ Therefore, the aminolysis of cyclic carbonates has been thoroughly investigated in order to understand and optimize the ring opening reaction. For this reason, the influence of many parameters such as solvent, temperature, catalyst, cyclic carbonate substituents or amine structure has been studied. ${ }^{22-24}$ However, depending of the final application, the use of solvent or catalyst is not always possible. Therefore, the choice of both cyclic carbonate and amine structures remains a crucial step. Five-membered cyclic carbonates are more reactive when they are substituted by electron withdrawing groups, because of increased electrophilicity of the carbon from the carbonyl group. ${ }^{25}$ On the other hand, primary amines with $\mathrm{NH}_{2}$ attached to a primary carbon atom with $\alpha$ or $\beta$ electron withdrawing substituents are the most reactive amines, while primary aromatic amines and aliphatic ones with $\mathrm{NH}_{2}$ attached to a secondary carbon atom are the less reactive ones. ${ }^{26}$ Furthermore, secondary amines can also react with cyclic carbonates but only at higher temperatures, around $90^{\circ} \mathrm{C}$ for the most reactive amines and up to $200{ }^{\circ} \mathrm{C}$ for sterically hindered ones. ${ }^{27}$ 
Recently, our team demonstrated the higher reactivity of primary $\beta$-hydroxylamines toward epoxy monomers compared to alkylamines. ${ }^{28}$ Indeed, 1,2-epoxy-3-phenoxypropane was fully converted with 1-amino-2-butanol after only $20 \mathrm{~min}$ at $60^{\circ} \mathrm{C}$ in bulk, whereas only $31 \%$ was consumed with butylamine under the same conditions and full conversion took 2 hours. In addition to high reactivity, the use of $\beta$-hydroxylamines also presents strong advantages. Indeed, biobased $\beta$-hydroxylamines can be easily synthesized by reacting biobased epoxides with aqueous ammonia. ${ }^{29,30}$ This one-step process is inexpensive, does not require complex purifications and can be easily implemented. While the carbonation of a polyfunctional epoxide affords a polyfunctional cyclic carbonate, the ring opening with aqueous ammonia leads to the equivalent polyfunctional $\beta$-hydroxylamines. ${ }^{30} \mathrm{Di}$-, tri- and tetra$\beta$-hydroxylamines were already reacted with polyfunctional cyclic carbonates by Blattmann et al. for the synthesis of $100 \%$ biobased PHU thermosets. ${ }^{31}$ However, the reactivity of the $\beta$-hydroxylamines were only assessed by comparing the gelation time of different formulations. The authors reported longer gelation times for the formulations containing higher amounts of $\beta$-hydroxylamines and concluded that they are less reactive, which is quite surprising in regards to their reactivity with epoxides.

We thus thoroughly investigated, for the first time, the aminolysis of a cyclic carbonate by comparing a $\beta$-hydroxylamine to non-functionalized alkylamine. Along with the kinetic study of the ethylene carbonate aminolysis with 1-amino-2-butanol and butylamine by ${ }^{1} \mathrm{H}$ NMR, quantum chemical calculations of the mechanism were carried out by the DFT method. The higher reactivity of $\beta$ hydroxylamines toward cyclic carbonates was then confirmed by rheological experiments and $100 \%$ biobased thermosets were synthesized and characterized by structural and thermo-mechanical analyses (IR, DSC, TGA, DMA). The higher reactivity of $\beta$-hydroxylamines was confirmed by the gelation time gap between the two formulations studied.

\section{Experimental}

\section{Materials}

Ethylene carbonate (purity 99\%) was purchased from Alfa Aesar (Kandel, Germany). Butylamine (purity 99.5\%), tetrabutylammonium bromide (purity 99\%) and trimethylolpropane triglycidyl ether were purchased from Sigma-Aldrich Merck (Darmstadt, Germany). 1-Amino-2-butanol (purity 98.5\%) was purchased from TCI EUROPE N.V (Zwijndrecht, Belgium). N,N'-Carbodiimidazole (purity 98\%) and glycerol carbonate (purity 90\%) were purchased from abcr GmbH (Karlsruhe, Germany). Aqueous ammonia $\left(25 \% \mathrm{NH}_{3}\right)$ and ethyl acetate were purchased from VWR International S.A.S (Fontenay-sous- 
Bois, France). Pripol ${ }^{\mathrm{TM}} 1012$ was purchased from Croda (East Cowick, United Kingdom). All materials were used as received. The NMR solvent $\mathrm{CDCl}_{3}$ was purchased from Eurisotop (Saint-Aubin, France).

\section{Characterizations}

\section{Nuclear Magnetic Resonance}

Proton Nuclear Magnetic Resonance ( ${ }^{1} \mathrm{H}$ NMR) analyses were carried out in deuterated chloroform $\left(\mathrm{CDCl}_{3}, 99.50 \%\right.$ isotopic purity) using Bruker Avance III $400 \mathrm{MHz} \mathrm{NMR}$ spectrometer at a temperature of $25^{\circ} \mathrm{C}$.

\section{Fourier Transform Infrared Spectroscopy}

Infrared (IR) spectra were recorded on a Nicolet 210 Fourier transform infrared (FTIR) spectrometer. The characteristic IR absorptions mentioned in the text are reported in $\mathrm{cm}^{-1}$. Materials analyses were recorded using an ATR accessory.

\section{Thermogravimetric Analyses}

Thermogravimetric Analyses (TGA) were carried out using TG 209F1 apparatus (Netzch). Approximately $10 \mathrm{mg}$ of sample were placed in an aluminum crucible and heated from room temperature to $580^{\circ} \mathrm{C}$ at a heating rate of $20^{\circ} \mathrm{C} / \mathrm{min}$ under nitrogen atmosphere $(60 \mathrm{~mL} / \mathrm{min})$.

\section{Differential Scanning Calorimetry}

Differential Scanning Calorimetry (DSC) analyses were carried out using a NETZSCH DSC200F3 calorimeter, which was calibrated using indium, $n$-octadecane and $n$-octane standards. Nitrogen was used as purge gas. Approximately $10 \mathrm{mg}$ of sample were placed in a perforated aluminum pan and the thermal properties were recorded between $-150{ }^{\circ} \mathrm{C}$ and $190{ }^{\circ} \mathrm{C}$ at $20^{\circ} \mathrm{C} / \mathrm{min}$ to observe the glass transition temperature. The $\mathrm{T}_{\mathrm{g}}$ values were measured on the second heating ramp to erase the thermal history of the polymer. All the reported temperatures are average values.

\section{Dynamic mechanical analyses}

Dynamic mechanical analyses (DMA) were carried out on Metravib DMA 25 with Dynatest 6.8 software. Samples were tested according to uniaxial tension mode while heating at a rate of $3{ }^{\circ} \mathrm{C} / \mathrm{min}$ from $-100{ }^{\circ} \mathrm{C}$ to $100{ }^{\circ} \mathrm{C}$ at a frequency of $1 \mathrm{~Hz}$ with a fixed strain of $10^{-5} \mathrm{~m}$. All the thermosets were analyzed at least two times for repeatability. 


\section{Rheology experiments}

Gelation times were measured using a Thermo Fisher HAAKE MARS rheometer with a plate-plate geometry with a diameter of $25 \mathrm{~mm}$. Gelation times were analyzed by the crossover of the storage modulus $\left(\mathrm{G}^{\prime}\right)$ and loss modulus $\left(\mathrm{G}^{\prime \prime}\right)$ during an oscillatory experiment at $1 \mathrm{~Hz}$ at $80{ }^{\circ} \mathrm{C}$ and $10 \mathrm{~Pa}$ of stress, according to the previously determined linear domain.

\section{Titration of the amine equivalent weight of Priamine ${ }^{\mathrm{TM}} 1071$ by ${ }^{1} \mathrm{H}$ NMR}

The Amine Equivalent Weight (AEW) is the amount of product needed for one equivalent of reactive amine function. It was determined by ${ }^{1} \mathrm{H}$ NMR using an internal standard (benzophenone). A known mass of product and benzophenone were poured into an NMR tube and $500 \mu \mathrm{L}$ of $\mathrm{CDCl}_{3}$ were added. The AEW was determined using Equation 1 by comparing the integration value of the signals assigned to the benzophenone protons $(7.5-7.8 \mathrm{ppm})$ with the integration of the signals arising from amine moiety protons (2.67 ppm).

\section{Equation 1}

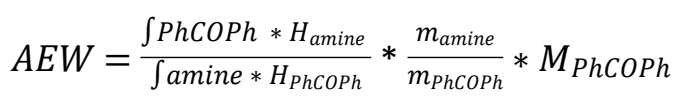

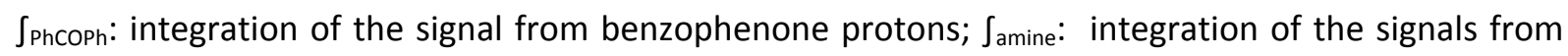
protons in $\alpha$ of the amine function; $\mathrm{H}_{\text {amine }}$ : number of protons in $\alpha$ of the amine function; $\mathrm{H}_{\text {PhCOPh }}$ : number of benzophenone protons; $m_{\text {amine: }}$ product mass; $m_{\text {Phcoph }}$ : benzophenone mass; $M_{\text {Phcoph }}$ : benzophenone molecular weight.

\section{Determination of the secondary amine content of TMPT- $\beta-\mathrm{HA}$ by ${ }^{13} \mathrm{C}$ NMR}

TMPT- $\beta$-HA was dissolved in $\mathrm{CD}_{3} \mathrm{OD}$ at a concentration of $200 \mathrm{mg} / \mathrm{mL}$ and ${ }^{13} \mathrm{C}$ NMR spectra were carried out on a Bruker spectrometer Avance I at $25^{\circ} \mathrm{C}$ using the following parameters: $30 \mathrm{kHz}$ for spectral width, $10 \mathrm{kHz}$ for transmitter frequency offset, $2 \mathrm{~s}$ for acquisition time, 2864 scans. Quantitative conditions could be approached (as best without T1 measurement) with a $30^{\circ}$ pulse $(3.3 \mu \mathrm{s})$ and a relaxation delay of $30 \mathrm{~s}(\mathrm{D} 1) .{ }^{1} \mathrm{H}$ decoupling was applied during acquisition (waltz16 method with a pulse of $90 \mu \mathrm{s})$. Pulse program was zgig30 from the Bruker library. The spectrum was calibrated with the $\mathrm{CH}_{3}$ peak at $8.00 \mathrm{ppm}$.

\section{Titration of the amine equivalent weight of TMPT- $\beta-\mathrm{HA}$ by ${ }^{13} \mathrm{C}$ NMR}

The AEW of TMPT- $\beta$-Ha could not be measured by ${ }^{1} \mathrm{H}$ NMR because of the overlap of the primary and secondary amines $\alpha$ proton peaks. Therefore, it was determined by ${ }^{13} \mathrm{C}$ NMR using the approached quantitative conditions, presented in the previous section, with an additional internal standard (phenol). A known weight of product and phenol were poured into an NMR tube and $500 \mu \mathrm{L}$ of $\mathrm{CDCl}_{3}$ 
were added. The AEW was determined using Equation 2 by comparing the integrals of the phenol carbons (148-160 ppm) and of the primary amine moiety carbons (44.26-45.14 ppm).

Equation 2

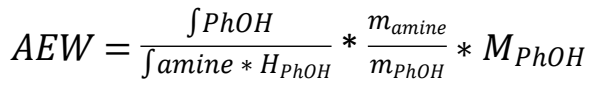

$\int_{\mathrm{PhOH}}$ : integration value of the phenol carbons peak; $\int_{\text {amine }}$ : integration value of the peak from carbons in $\alpha$ of the primary amine function; $\mathrm{H}_{\text {РhОH }}$ : number of phenol carbons; $\mathrm{m}_{\text {amine }}$ : product mass; $\mathrm{m}_{\text {PhOH }}$ : benzophenone mass; $\mathrm{M}_{\text {Рhон }}$ : phenol molecular weight.

\section{Titration of the carbonate equivalent weight by ${ }^{1} \mathrm{H}$ NMR}

The Carbonate Equivalent Weight (CEW) is the amount of product needed for one equivalent of reactive cyclic carbonate function. It was determined by ${ }^{1} \mathrm{H}$ NMR using an internal standard (benzophenone). A known weight of product and benzophenone were poured into an NMR tube and $500 \mu \mathrm{L}$ of $\mathrm{CDCl}_{3}$ were added. The CEW was determined using Equation 3 by comparing the integration values of the peak corresponding to benzophenone protons $(7.5-7.8 \mathrm{ppm})$ with those of the cyclic carbonate moiety protons (4.81 ppm for TMPTC and 4.91 ppm for Pripol- $\mathrm{C}_{5}$ ).

Equation 3

$$
C E W=\frac{\int P h C O P h}{\int \text { carbonate } * H_{\text {carbonate }}} * \frac{m_{\text {carbonate }}}{m_{\text {PhCOPh }}} * M_{\text {PhCOPh }}
$$

$\int_{\text {PhCoph }}$ integration value of the signal from benzophenone protons; $\int_{\text {carbonate }}:$ integration value of the signal from protons in $\alpha$ of the carbonate function; $\mathrm{H}_{\text {carbonate }}$ number of protons in $\alpha$ of the carbonate function; $\mathrm{H}_{\text {PhCOPh }}$ : number of benzophenone protons; $\mathrm{m}_{\text {carbonate: }}$ : product mass; $\mathrm{m}_{\text {Phcoph }}$ : benzophenone mass; $M_{\text {phcoph }}$ : benzophenone molecular weight.

\section{Cross-linking density}

From rubber elasticity theory, the uniaxial stretching was studied on the rubbery plateau at $T>T_{\alpha}+50$, and at very small deformations. Under these hypotheses, the cross-linking density $\left(v^{\prime}\right)$, can be obtained from Equation 4, where $\mathrm{E}^{\prime}$ is the storage modulus $(\mathrm{Pa}), \mathrm{R}$ is gas constant $\left(8.314 \mathrm{~J}^{\mathrm{K}} \mathrm{K}^{-1} \cdot \mathrm{mol}^{-1}\right)$ and $\mathrm{T}_{\alpha}$ is the temperature, in $\mathrm{K}$, of transition from vitreous to rubber domain, determined at the maximum of the $\tan \delta$ curve. Calculated values are only qualitative and not absolute.

Equation 4

$$
v^{\prime}=\frac{E_{a t T \alpha+50}^{\prime}}{3 R T_{\alpha+50}}
$$




\section{Swelling index}

Three samples from the same material, of around $20 \mathrm{mg}$ each, were separately immersed in THF for $24 \mathrm{~h}$. The swelling index (SI) was calculated using Equation 5, where $\mathrm{m}_{2}$ is the mass of the swollen material and $m_{1}$ is the initial mass. Reported swelling index are average values of the three sample.

Equation 5

$$
S I=\frac{m_{2}-m_{1}}{m_{1}} \times 100
$$

\section{Gel Content}

After the $\mathrm{SI}$ measurements, the three samples were dried in a ventilated oven at $70{ }^{\circ} \mathrm{C}$ for $24 \mathrm{~h}$. The gel content (GC) was calculated using Equation 6 , where $m_{3}$ is the mass of the dried material and $m_{1}$ is the initial mass. Reported gel content are average values of the three sample.

Equation 6 $\quad G C=\frac{m_{3}}{m_{1}} \times 100$

\section{General procedure of ${ }^{1} \mathrm{H}$ NMR kinetic monitoring}

Typically, $8.8 \mathrm{mg}$ of ethylene carbonate $\left(0.1 \mathrm{mmol}, 1\right.$ eq.) were placed in $1.490 \mathrm{~g}$ of $\mathrm{CDCl}_{3}(1 \mathrm{~mL})$ in a hemolysis tube, followed by stirring using a vortex. Once the carbonate was fully dissolved, the desired amount of amine was carefully added and the mixture was homogenized with $30 \mathrm{~s}$ of vortex stirring. Then, $450 \mu \mathrm{L}$ of the solution were transferred to a NMR tube and the reaction was monitored at fixed time intervals by ${ }^{1} \mathrm{H}$ NMR analyses using a Bruker Avance III $400 \mathrm{MHz}$ NMR spectrometer.

\section{Computational details}

All calculations were carried out using the Gaussian09 suite of programs. ${ }^{32}$ Gas-phase geometry optimizations were performed without any symmetry constraint using the BP86 functional and the 6$311 \mathrm{G}(\mathrm{d}, \mathrm{p})$ basis functions for all atoms. A correction for dispersion was also included during the geometry optimizations using Grimme's D3 empirical method (BP86-D3). ${ }^{33}$ All final geometries were characterized as local minima (or first-order saddle points for the transitions states) by verifying that all second derivatives of the energy were positive (or that only one was negative). Thermochemical corrections were obtained on the basis of frequency calculations, using the standard approximations (ideal gas, rigid rotor and harmonic oscillator). The final free energy values also included a solvation correction in chloroform, estimated by the polarizable continuum model using the SMD model with standard parameters. ${ }^{34} \mathrm{~A}$ further correction of $1.95 \mathrm{kcal} / \mathrm{mol}$ was applied to bring the $\mathrm{G}$ values from the gas phase $(1 \mathrm{~atm})$ to the solution $(1 \mathrm{~mol} / \mathrm{L})$ standard state. ${ }^{35}$ The Cartesian coordinates and energies of all optimized structures are deposited as Supporting Information. 


\section{Synthesis}

\section{Synthesis of trimethylolpropane tricarbonate (TMPTC)}

Trimethylolpropane triglycidyl ether (TMPTGE; $20 \mathrm{~g}, 0.139 \mathrm{~mol}$ ) and tetrabutylammonium bromide (TBAB; $0.6 \mathrm{~g}, 1.86 \mathrm{mmol}$ ) were solubilized in $50 \mathrm{~mL}$ of AcOEt and added to a $100 \mathrm{~mL}$ sealed reactor. The reaction was carried out at $80^{\circ} \mathrm{C}$ under 20 bars of $\mathrm{CO}_{2}$ for $72 \mathrm{~h}$. The crude mixture was then washed with water and brine to remove TBAB. The organic layer was then dried with magnesium sulfate and under vacuum. The pure product was obtained as a yellowish viscous liquid (yield $=88 \%$ ).

${ }^{1} \mathrm{H}$ NMR $\left(400 \mathrm{MHz}, \mathrm{CDCl}_{3}\right): \delta / \mathrm{ppm}=0.82\left(\mathrm{t}, \mathrm{CH}_{3}\right), 1.36\left(\mathrm{~m}, \mathrm{CH}_{2}\right), 3.24-4.00\left(\mathrm{~m}, \mathrm{CH}_{2}\right), 4.39\left(\mathrm{~m}, \mathrm{CH}_{2}\right), 4.49$ $\left(\mathrm{t}, \mathrm{CH}_{2}\right), 4.81(\mathrm{~m}, \mathrm{CH})$.

\section{Synthesis of Pripol- $\mathrm{C}_{5}$}

Pripol $^{\mathrm{TM}} 1012$ (30 g, $0.12 \mathrm{~mol}, 1$ eq.) was solubilized in $60 \mathrm{~mL}$ of AcOEt in a round-bottomed flask. N,N'carbodiimidazole ( $22.45 \mathrm{~g}, 0.14 \mathrm{~mol}, 1.2 \mathrm{eq}$.) was dissolved in $60 \mathrm{~mL}$ of AcOEt and the resulting solution was then added dropwise to the Pripol ${ }^{\mathrm{TM}} 1012$ solution at $25^{\circ} \mathrm{C}$. The reaction was monitored by ${ }^{1} \mathrm{H}$ NMR until full conversion of the acid to the imidazolide intermediate. Then, glycerol carbonate (16.35 g, 0.14 mol, 1.2 eq.) was added to the reaction. The reaction was carried out at $25{ }^{\circ} \mathrm{C}$ for 3 days until full conversion of imidazolide to ester functions. The crude mixture was first washed with a $5 \% \mathrm{HCl}$ aqueous solution and then with a saturated $\mathrm{NaHCO}_{3}$ aqueous solution. Finally, the mixture was washed with brine and dried with magnesium sulfate and under vacuum. The pure product was obtained as a yellow oil (yield $=85 \%$ ).

${ }^{1} \mathrm{H}$ NMR $\left(400 \mathrm{MHz}, \mathrm{CDCl}_{3}\right): \delta / \mathrm{ppm}=0.87\left(\mathrm{~m}, \mathrm{CH}_{3}\right), 1.00-1.48\left(\mathrm{~m}, \mathrm{CH}_{2}\right), 1.48-1.78\left(\mathrm{~m}, \mathrm{CH} / \mathrm{CH}_{2}\right), 1.78-2.17$ $\left(\mathrm{m} ; \mathrm{CH}_{2}\right), 2.36\left(\mathrm{t}, \mathrm{CH}_{2}\right), 4.21-4.62\left(\mathrm{~m}, \mathrm{CH}_{2}\right), 4.91(\mathrm{~m}, \mathrm{CH})$.

\section{Synthesis of trimethylolpropane tri- $\beta$-hydroxylamine (TMPT- $\beta-H A$ )}

TMPTGE (10 g, $0.099 \mathrm{~mol}, 1$ eq.) was dissolved in $139 \mathrm{~mL}$ of a $25 \% \mathrm{NH}_{3}$ aqueous solution (0.99 mol, 10 eq.) in a sealed reactor. The reaction was carried out at $100^{\circ} \mathrm{C}$ for $4 \mathrm{~h}$. The ammonia solution was then evaporated with a rotatory evaporator and then freeze-dried to remove water traces. The pure product was obtained as a yellow viscous liquid (yield $=99 \%$ )

${ }^{1} \mathrm{H}$ NMR (400 MHz, CD $\left.\mathrm{CD}_{3} \mathrm{OD}\right): \delta / \mathrm{ppm}=0.87\left(\mathrm{t}, \mathrm{CH}_{3}\right), 1.40\left(\mathrm{~m}, \mathrm{CH}_{2}\right), 2.51-3.09\left(\mathrm{~m}, \mathrm{CH}_{2}-\mathrm{NH}_{2}\right), 2.28-3.77(\mathrm{~m}$, $\left.\mathrm{CH}_{2}\right), 3.82(\mathrm{~m}, \mathrm{CH}-\mathrm{OH})$. 
${ }^{13} \mathrm{C}$ NMR (101 MHz, CD $\left.3 \mathrm{OD}\right):$ /ppm = $8.00\left(\mathrm{CH}_{3}\right), 23.60\left(\mathrm{CH}_{2}\right), 24.09\left(\mathrm{CH}_{2}\right), 43.63(\mathrm{C}), 44.26-45.14\left(\mathrm{CH}_{2^{-}}\right.$ $\left.\mathrm{NH}_{2}\right), 54.38\left(\mathrm{CH}_{2}-\mathrm{NH}-\mathrm{CH}_{2}\right.$ dimer), 65.32-66.15 ( $\mathrm{CH}-\mathrm{OH}$ dimer), $70.39(\mathrm{CH}-\mathrm{OH}), 73.12\left(\mathrm{CH}_{2}\right), 74.89\left(\mathrm{CH}_{2}\right)$, $77.08\left(\mathrm{CH}_{2}\right)$.

\section{General procedure of PHU thermoset synthesis}

Materials were synthetized with a cyclic carbonate/amine molar ratio of $1 / 1$. The amine and carbonate masses were calculated with the Equation 7 and Equation 8, respectively, where $\mathrm{n}_{\text {carbonate }}$ and $\mathrm{n}_{\text {amine }}$ are the number of moles of cyclic carbonate and amine, respectively, and AEW is the amine equivalent weight and CEW is the carbonate equivalent weight.

$$
\begin{array}{ll}
\text { Equation } 7 & m_{\text {amine }}=\frac{n_{\text {carbonate }}}{\mathrm{AEW}} \\
\text { Equation 8 } & m_{\text {carbonate }}=\frac{n_{\text {amine }}}{\mathrm{CEW}}
\end{array}
$$

The cyclic carbonate and the amine were stirred using a SpeedMixer ${ }^{\mathrm{TM}}$ under vacuum for 5 minutes at $2500 \mathrm{rpm}$. Then, the resulting homogeneous mixture was poured in a silicon mold and cured at $80^{\circ} \mathrm{C}$ for $10 \mathrm{~h}$, then $6 \mathrm{~h}$ at $120^{\circ} \mathrm{C}$ and finally $1 \mathrm{~h}$ at $150^{\circ} \mathrm{C}$.

\section{Results \& Discussion}

\section{Kinetic and DFT studies}

The aminolysis was first studied by ${ }^{1} \mathrm{H}$ NMR using ethylene carbonate (EC) as a model five-membered cyclic carbonate, comparing the reactivity of butylamine $\left(\mathrm{BuNH}_{2}\right)$ and 1-amino-2-butanol $\left(\mathrm{BuNH}_{2}-\right.$ $\beta O H)$. The conversion was monitored by measuring the intensity of the EC signal in ${ }^{1} \mathrm{H}$ NMR $(\delta=4.41$ ppm) over time (Figure S1 and Figure S2). The resulting conversion plots are presented in Figure 1. 
Butylamine<smiles>CCCCNC(=O)OCCO</smiles>

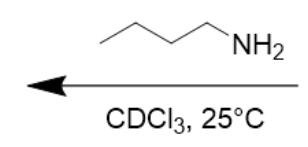

$\mathrm{CDCl}_{3}, 25^{\circ} \mathrm{C}$ 1-amino-2-butanol

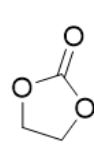

Ethylene carbonate

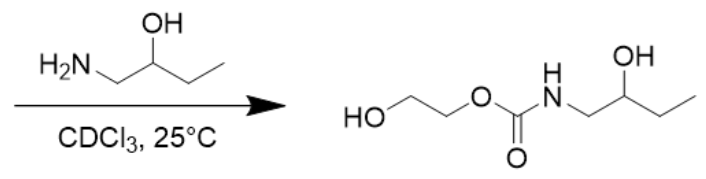

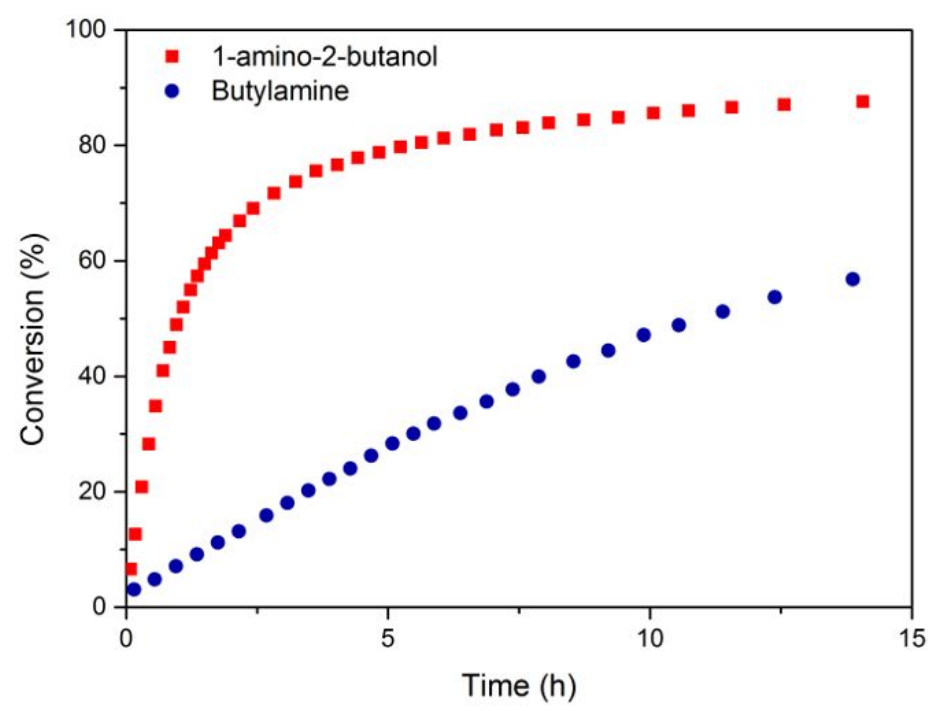

Figure 1 : Comparative kinetic monitoring of the ethylene carbonate $(1 \mathrm{~mol} / \mathrm{L})$ ring opening with butylamine $(1$ $\mathrm{mol} / \mathrm{L})$ and 1-amino-2-butanol $(1 \mathrm{~mol} / \mathrm{L})$ by ${ }^{1} \mathrm{H} \mathrm{NMR} \mathrm{in} \mathrm{CDCl}_{3}$ at $25^{\circ} \mathrm{C}$.

The 1-amino-2-butanol is much more reactive compared to butylamine. Indeed, after one hour, the reaction with the $\beta$-hydroxylamine reached a $50 \%$ conversion against only $7 \%$ for the alkylamine. However, even after 14 hours of reaction with $\beta$-hydroxylamine, the conversion was stalling around $85 \%$. This phenomenon is well-known for the aminolysis reaction, indeed, the formation of the new hydroxyl group during the reaction creates a dense network of hydrogen bonds, increasing the viscosity and decreasing the reagents mobility, which prevents quantitative conversion. Even though the 1-amino-2-butanol contains a pendant hydroxyl group, which further increases the density of hydrogen bonds, the EC conversion could still reach $85 \%$, which is comparable to the literature values (around 80\%). ${ }^{25}$ On the other hand, the reaction with butylamine only reached a 57\% conversion after $14 \mathrm{~h}$. Therefore, the 1-amino-2-butanol hydroxyl group allows to strongly increase the amine reactivity. To understand this effect, experimental (kinetic) and theoretical (DFT calculations) mechanistic investigations were carried out.

Kinetic studies gave us access to the rate law and rate constants for the reaction with each amine. To this end, observed rate constants were first obtained using a significant excess (from 10 to 50 eq.) of 1-amino-2-butanol and butylamine compared to the EC concentration $(0.1 \mathrm{~mol} / \mathrm{L})$. The EC decay followed a first order rate law in each case, see Figure 2 . The pseudo-first order rate constants, $k_{\text {obs }}$ 
were determined with Equation 9 and are given in Table 1 . The dependence of $k_{\text {obs }}$ on the amine concentration is shown in Figure 3. The trends are clearly non-linear with an upward curvature (positive second derivative), indicating that the reaction order in amine is greater than one.

\section{Equation 9: $\ln [E C]=\ln [E C]_{0}-k_{\text {obs }} t$}
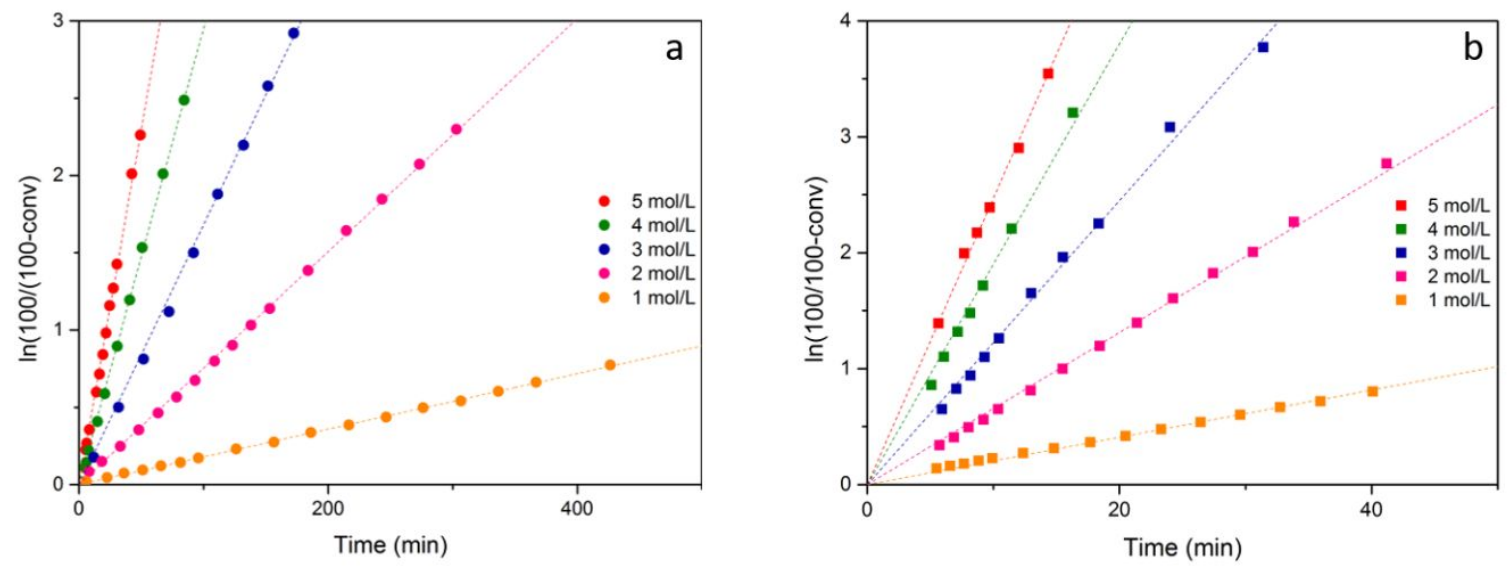

Figure 2 : Kinetic of the aminolysis of ethylene carbonate $(0.1 \mathrm{~mol} / \mathrm{L})$ with (a) butylamine and (b) 1amino-2-butanol at different concentrations by ${ }^{1} \mathrm{H} N \mathrm{NM}$ in $\mathrm{CDCl}_{3}$ at $25^{\circ} \mathrm{C}$.

Table 1: Pseudo-first order rate constants for the ethylene carbonate $(0.1 \mathrm{~mol} / \mathrm{L})$ aminolysis in $\mathrm{CDCl}_{3}$ at $25^{\circ} \mathrm{C}$.

\begin{tabular}{|c|c|c|c|}
\hline$\left[\mathrm{BuNH}_{2}-\mathrm{BOH}\right](\mathrm{mol} / \mathrm{L})$ & $k_{\text {obs }} \times 10^{3}\left(\mathrm{~s}^{-1}\right)$ & {$\left[\mathrm{BuNH}_{2}\right](\mathrm{mol} / \mathrm{L})$} & $k_{\text {obs }} \times 10^{3}\left(\mathrm{~s}^{-1}\right)$ \\
\hline 0.96 & $20.4 \pm 0.2$ & 1.04 & $1.795 \pm 0.006$ \\
\hline 2.01 & $65.6 \pm 0.5$ & 2.19 & $7.54 \pm 0.03$ \\
\hline 2.96 & $122 \pm 2$ & 2.99 & $16.8 \pm 0.1$ \\
\hline 4.02 & $190 \pm 3$ & 4.08 & $29.5 \pm 0.2$ \\
\hline 4.93 & $247 \pm 2$ & 5.07 & $46.0 \pm 0.4$ \\
\hline
\end{tabular}

The data were analyzed on the basis of Equation 10, as already described by Zabalov et al. ${ }^{36}$ for the reaction of EC with butylamine in $n$-butanol and dioxane:

$$
\text { Equation } 10 \quad k_{\text {obs }}=k_{1}[\text { Amine }]+k_{2}[\text { Amine }]^{2}
$$

The meaning of this rate law is that the reaction may occur by two parallel channels with the participation of one $\left(k_{1}\right)$ and two $\left(k_{2}\right)$ amine molecules. The $k_{1}$ and $k_{2}$ values were determined by fitting Equation 2 to the data in Table 1, with a correlation coefficient $R^{2}>0.99$ in each case, and the results are given in Table 2. 


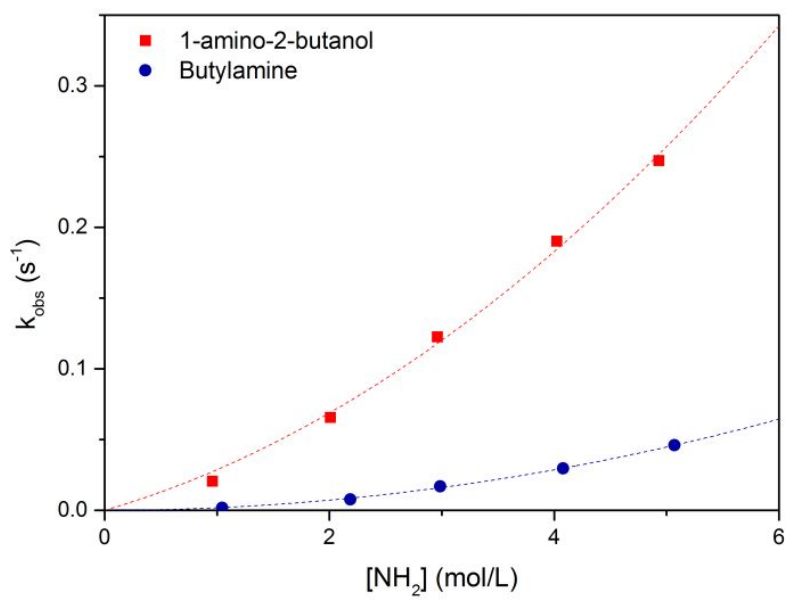

Figure 3 : Dependence of $\mathrm{k}_{\text {obs }}$ of ethylene carbonate reaction with butylamine and 1-amino-2-butanol in $C D C l_{3}$ on amine concentration at $25^{\circ} \mathrm{C}$.

Table 2: Rate constant for the ethylene carbonate aminolysis in $\mathrm{CDCl}_{3}$ at $25^{\circ} \mathrm{C}$.

\begin{tabular}{ccc} 
& $k_{1} \times 10^{3}\left(\mathrm{~L} \mathrm{~mol}^{-1} \cdot \mathrm{s}^{-1}\right)$ & $\boldsymbol{k}_{\mathbf{2}} \times 10^{3}\left(\mathrm{~L}^{\mathbf{2}} \cdot \mathrm{mol}^{-2} \cdot \mathrm{s}^{-1}\right)$ \\
\hline 1-amino-2-butanol & $23 \pm 3$ & $5.6 \pm 0.9$ \\
Butylamine & 0 & $1.79 \pm 0.02$
\end{tabular}

These results are interesting for a few reasons. First of all, the rate law for the reaction with the butylamine exhibits a pure second order for the amine reagent, without significant contribution of the pathway involving only one amine molecule. This result is in contrast with those reported by Zabalov et al. for the same reaction in other solvents, where both pathways contributed to the reaction with $\left[k_{1}\left(\mathrm{~L} \mathrm{~mol}^{-1} \mathrm{~s}^{-1}\right) ; k_{2}\left(\mathrm{~L}^{2} \mathrm{~mol}^{-2} \mathrm{~s}^{-1}\right)\right]=\left(0.75 \cdot 10^{-5} ; 1.88 \cdot 10^{-5}\right)$ in $n$-butanol at $28^{\circ} \mathrm{C}^{36}$ and $\left(0.24 \cdot 10^{-5} ; 2.5 \cdot 10^{-5}\right)$ in DMSO at $55^{\circ} \mathrm{C} .{ }^{37}$ However, the $k_{1}$ pathway was also found insignificant in dioxane $\left(k_{1}=8.4 \cdot 10^{-8} \mathrm{~L} \mathrm{~mol}^{-1}\right.$ $\mathrm{s}^{-1}$, vs. $k_{2}=2.98 \cdot 10^{-5} \mathrm{~L}^{2} \mathrm{~mol}^{-2} \mathrm{~s}^{-1}$ at $\left.28^{\circ} \mathrm{C}\right) \cdot{ }^{36}$ Secondly, the reaction in chloroform is much faster, since $k_{2}$ $=(179 \pm 2) \cdot 10^{-5} \mathrm{~L}^{2} \mathrm{~mol}^{-2} \mathrm{~s}^{-1}$ at $25^{\circ} \mathrm{C}$. The rate law for the reaction with 1-amino-2-butanol, on the other hand, in addition to having a greater $k_{2}$ value, also shows a relevant contribution of the pathway involving a single amine molecule. The involvement of a single amine molecule is not surprising when the reaction is conducted in a solvent that can participate in the proton transfer chain (e.g. $n$-butanol), but is less obvious in a solvent that cannot ensure this role such as chloroform.

A rationalization of these differences requires a detailed analysis of the reaction mechanism. The EC aminolysis has previously been analyzed by computational methods by Zabalov et al. ${ }^{36-38}$ Two main pathways, concerted and stepwise, have been highlighted as shown in Scheme 1. In the concerted pathway, the proton from the nucleophile is directly transferred to the leaving group in one step, 
whereas the stepwise mechanism involves proton transit through the carbonyl $\mathrm{O}$ atom with generation of a tetrahedral intermediate. However, a simple two-molecule collision (i.e. carbonyl substrate and nucleophile) leads to high barriers in both cases because of the strained 4-membered cycles in the transition state, Scheme 1(a). The reaction has a much lower barrier when assisted by at least one additional proton shuttle molecule $(\mathrm{H}-\mathrm{X})$, which must have amphiphilic $\mathrm{H}$-bonding properties, namely both proton and acceptor. Scheme 1 (b) shows the example with only one $\mathrm{H}-\mathrm{X}$ molecule. In a first computational study of the EC aminolysis by $\mathrm{MeNH}_{2}$, Zabalov et al. considered only the concerted pathway with one $\mathrm{H}-\mathrm{X}$ molecule $\left(\mathrm{MeNH}_{2}\right.$ or $\mathrm{MeOH}$, models of the $n-\mathrm{BuNH}_{2}$ reactant and $n-\mathrm{BuOH}$ solvent). ${ }^{36} \mathrm{~A}$ subsequent thorough analysis of the effect of several $\mathrm{MeOH}$ molecules (up to six) for both concerted and stepwise mechanisms revealed the presence of several distinct pathways with similar activation barrier and a complex role of the $\mathrm{H}$-bonding solvent, including the possible stabilization of zwitterionic intermediates (e.g. EC-NHR $\cdots \mathrm{H}_{2} \mathrm{X}^{+}$). ${ }^{38}$ Finally, a recent contribution detailed the catalytic action of guanidine as $\mathrm{H}-\mathrm{X}$ for the $\mathrm{EC}$ aminolysis by $\mathrm{MeNH}_{2}$ in DMSO. ${ }^{37}$ The latter study underlines the assistance of the DMSO solvent for the stabilization of cyclic intermediates and transition states, even though it cannot be directly involved in proton transfer chains.

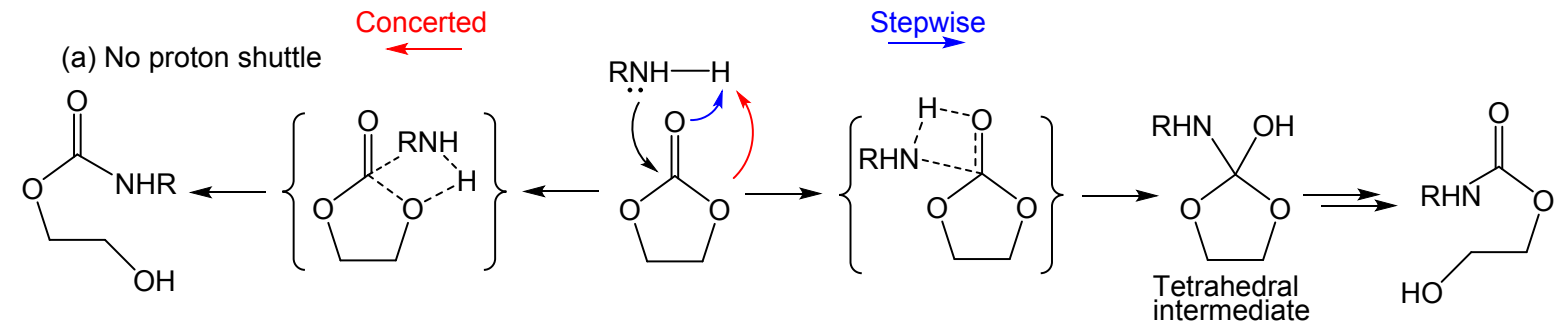

(b) Proton shuttle

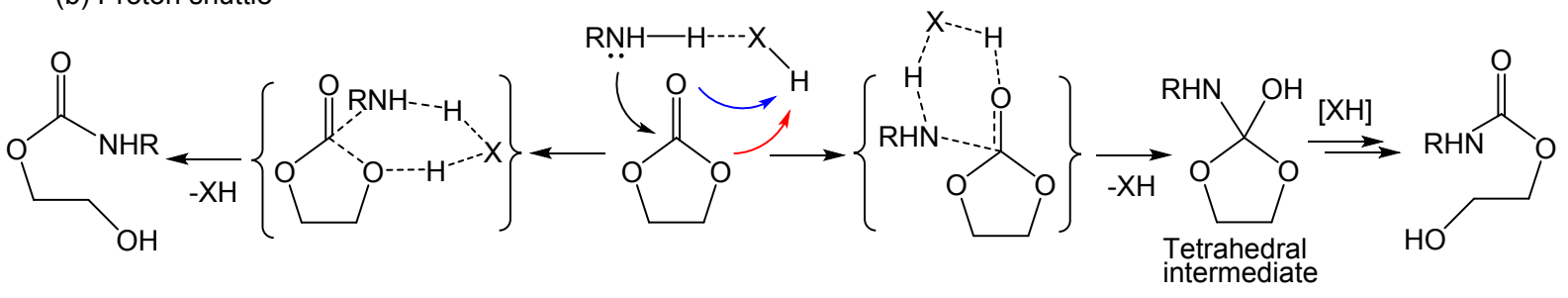

Scheme 1: Accepted mechanism for EC aminolysis.

This mechanistic scheme allows us to formulate the following hypotheses. The rate law for the reaction with butylamine in chloroform has only a second order term in amine because the chloroform solvent (like the previously investigated ${ }^{36}$ dioxane solvent) cannot play any assistance in the proton transfer chain. The $k_{2}$ value in chloroform is much higher than in $n$-butanol, dioxane or DMSO, because unlike all other solvents, chloroform cannot operate as a proton acceptor in $\mathrm{H}$-bonding. Therefore, the only proton acceptor in the reaction mixture is the EC substrate and consequently the amine can display enhanced reactivity as a proton donor. Conversely, chloroform is a weak proton donor in H-bonding because of the inductive effect of the $\mathrm{CCl}_{3}$ group. ${ }^{39}$ Therefore, it can assist the reaction at the transition 
state level through a screening of the developed negative charge, similarly (but better) to what was shown for the $\mathrm{CH}_{3}$ protons of DMSO. ${ }^{37}$ Concerning the reaction with 1-amino-2-butanol, we must rationalize two different effects: $i$ ) the greater $k_{2}$ value relative to butylamine; $i$ ) the contribution of a first-order term in amine $\left(k_{1}\right)$. The first effect can be easily rationalized, on the basis of the published computational analysis, by a transition state stabilization linked to the $\mathrm{H}$-bonding ability of the $\mathrm{OH}$ substituents. The second effect, given that the solvent cannot participate in the proton chain, suggests that the 1-amino-2-butanol must somehow allow a proton chain with the involvement of a single amine molecule.

The last proposition is the most relevant result of the present kinetic study and was therefore further analyzed by the DFT approach. We wish to underline that the purpose of this DFT investigation was not to quantitatively reproduce the relative rates and activation barriers, because the previously published has demonstrated that this requires the explicit inclusion of several solvent molecules and a lengthy investigation of a large number of pathways. ${ }^{36-38}$ We only wished to highlight the key role of the $\beta-\mathrm{OH}$ substituent in opening a single amine molecule pathway for the reaction. Therefore, no solvent molecules $\left(\mathrm{CHCl}_{3}\right)$ were explicitly included in the calculations and the effect of the solvent was only accounted for by the inclusion of a polarizable continuum. To capture the $\beta-\mathrm{OH}$ substituent effect, the chosen computational models for the reagents are $\mathrm{CH}_{3} \mathrm{CH}_{2} \mathrm{NH}_{2}$ (for the alkylamine) and $\mathrm{HOCH}_{2} \mathrm{CH}_{2} \mathrm{NH}_{2}$ (for 1_amino-2-butanol). In addition, our study was limited to the analysis of the stepwise process. Other computation details are given in the Experimental section.

We have comparatively analyzed three reaction pathways: $i)$ the two-molecule $\left(k_{2}\right)$ pathway for the alkylamine; ii) the two-molecule pathway for the alkoxylamine; iii) the one-molecule pathway $\left(k_{1}\right)$ for the alkoxylamine. The first one only serves as a reference since they do not present unprecedented features relatively to the work of Zabalov et al. ${ }^{36-38}$ The starting reactant complex features two $\mathrm{H}$ bonds, one between a first $\mathrm{EtNH}_{2}$ molecule as a donor and the $\mathrm{EC}$ carbonyl $\mathrm{O}$ atom as an acceptor, the second one between the second $\mathrm{EtNH}_{2}$ as a donor and the first $\mathrm{EtNH}_{2}$ as an acceptor, $\mathrm{EC} \cdots \mathrm{H}_{2} \mathrm{~N}(\mathrm{Et}) \cdots \mathrm{H}_{2} \mathrm{NEt}$. In the optimized structure, the $\mathrm{NH}_{2}$ group of the second $\mathrm{EtNH}_{2}$ molecule is suitably positioned for the nucleophilic attack at the carbonyl $\mathrm{C}$ atom. The transition state of each step, the tetrahedral intermediate and the product were optimized, yielding the reaction profiles shown in the SI (Figure S3). The highest free energy TS is that of the second step, leading from the tetrahedral intermediate to the opened product, at $16.3 \mathrm{kcal} / \mathrm{mol}$ from the reactant complex. The additional $\mathrm{EtNH}_{2}$ molecule remains $\mathrm{H}$-bonded as proton acceptor to the $\mathrm{OH}$ group in both intermediate and product, and also acts as proton donor to the carbonyl group in the product. 
The alkoxylamine two-molecule pathway is shown in Figure 4. The starting reactant complex shows strong $\mathrm{O}-\mathrm{H} \cdots \mathrm{O}$ interactions between the $\beta-\mathrm{OH}$ groups and the EC O atoms (a ring $\mathrm{O}$ atom for one alkoxylamine molecule and the $\mathrm{C}=\mathrm{O}$ atom for the second one) and an additional $\mathrm{N}-\mathrm{H} \cdots \mathrm{N}$ bond between the two amine functions. One $\mathrm{NH}_{2}$ function is once again correctly positioned in front of the $\mathrm{EC}$ carbonyl group ( $\mathrm{N} \cdots \mathrm{C}=2.69 \AA$ ) , even closer than for the $\mathrm{EtNH}_{2}$ system (3.06 $\AA$ ). $\mathrm{Th}^{\mathrm{N}} \mathrm{NH}_{2}$ addition to the carbonyl group is accompanied by transfer of a proton to the second amine $\mathrm{NH}_{2}$ function. The shuttle for this system occurs in two separate steps, via a charge-separated intermediate, $\left[(\mathrm{EC}) \mathrm{NHCH}_{2} \mathrm{CH}_{2} \mathrm{OH}\right]-\left[\mathrm{NH}_{3} \mathrm{CH}_{2} \mathrm{CH}_{2} \mathrm{OH}\right]^{+}$, which sits in a shallow minimum at $7.4 \mathrm{kcal}^{-1}$ from the reactant complex between two transition states (TS1 and TS1') at only slightly higher free energy. This intermediate has the formally negative $\mathrm{O}$ atom stabilized by two $\mathrm{H}$-bonds, one from the $\beta$-OH of the attacking hydroxylamine and the second one from the cationic $\mathrm{NH}_{3}$ group of the hydroxylamine shuttle. The tetrahedral intermediate obtained from the charge-separated species via TS1' (at $4.4 \mathrm{kcal}$ $\mathrm{mol}^{-1}$ ) must rearrange to prepare the proton transfer chain for the second step, leading to a second tetrahedral intermediate at $6.0 \mathrm{kcal} \mathrm{mol}^{-1}$, differing from the previous one only in the $\mathrm{H}$-bonding scheme. The second proton transfer occurs in one step via TS2. This corresponds to the highest point along the free energy profile and the overall barrier from the reactant complex (at $11.4 \mathrm{kcal} \mathrm{mol}^{-1}$ ) is significantly reduced relative to that of the $\mathrm{EtNH}_{2}$ system $\left(16.3 \mathrm{kcal} \mathrm{mol}{ }^{-1}\right)$. The fundamental steps of the two pathways are the same, but the two additional $\mathrm{O}-\mathrm{H} \cdots \mathrm{O}$ interactions that remain present throughout the reaction profile have a greater stabilizing effect on the intermediates, transition states and product than on the reactant complex. 


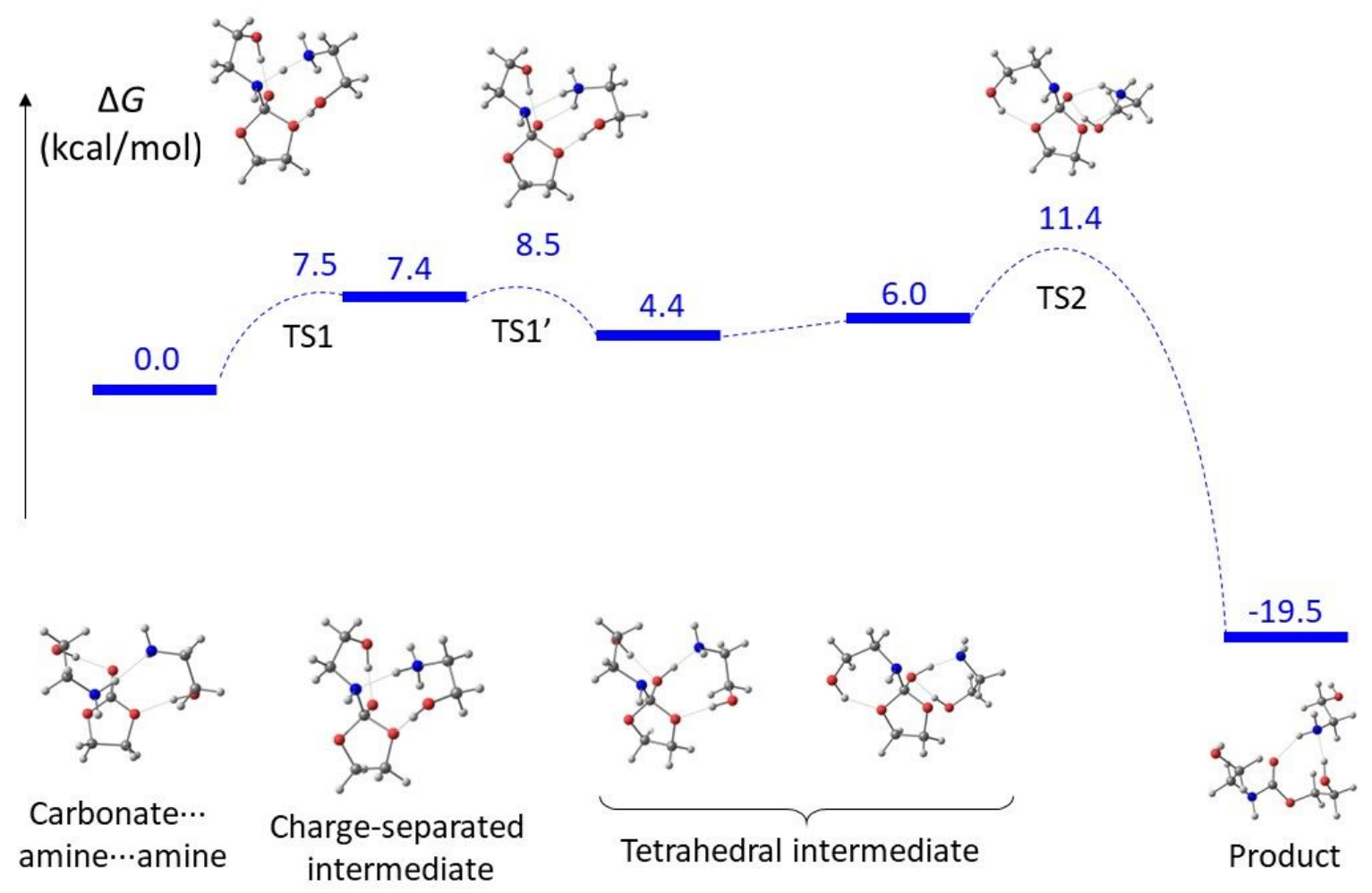

Figure 4 : Free-energy profile for the two-amine-molecule pathway of the ethylene carbonate aminolysis with $\mathrm{HOCH}_{2} \mathrm{CH}_{2} \mathrm{NH}_{2}$.

The pathway involving only one hydroxylamine molecule is illustrated in Figure 5 . The most stable reactant configuration features an $\mathrm{H}$-bond between the amine $\beta-\mathrm{OH}$ substituent as proton donor and the $\mathrm{EC}$ carbonyl $\mathrm{O}$ atom as proton acceptor. Once again, the $\mathrm{NH}_{2}$ group is properly positioned for the nucleophilic attack at the carbonyl $\mathrm{C}$ atom. The transition state of the first step (TS1) leading to the tetrahedral intermediate features the assistance by the $\beta-\mathrm{OH}$ group in an intramolecular proton shuttle with a 6-membered ring. It has a higher energy, relative to the reactant complex $\left(24.8 \mathrm{kcal} \mathrm{mol}^{-1}\right)$, than those of the two-amine pathways with $\mathrm{EtNH}_{2}$ or $\mathrm{HOCH}_{2} \mathrm{CH}_{2} \mathrm{NH}_{2}$, because the involvement of the $\mathrm{OH}$ group in the proton shuttle requires the adoption of a strained 5-membered ring for the hydroxylamine. The intermediate generated from TS1 (at $12.8 \mathrm{kcal} \mathrm{mol}^{-1}$ ) maintains the $\mathrm{O}-\mathrm{H} \cdots \mathrm{O}$ interaction between the generated $\mathrm{OH}$ group as a proton donor and the hydroxylamine $\beta-\mathrm{OH}$ group as a proton acceptor (1.85 $\AA$ ), but the $\beta$ - $\mathrm{OH}$ group cannot form a strong $\mathrm{H}$-bond as a proton donor with the residual $\mathrm{NH}$ function because of the 5-membered ring strain $(\mathrm{H} \cdots \mathrm{N}=2.40 \AA)$. In order to prepare for the second step, the $\beta-\mathrm{OH}$ group must move from the $\mathrm{N}$ atom toward the ring $\mathrm{O}$ atom. The resulting configuration is optimized with a minimum at nearly the same energy $\left(13.6 \mathrm{kcal} \mathrm{mol}^{-1}\right)$ and features

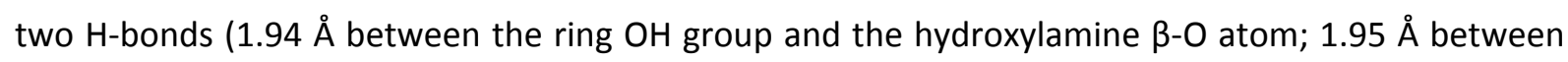
the $\beta$-OH group and the ring $\mathrm{O}$ atom). The next transition state (TS2) involves, like TS1, the participation 
of the $\beta-\mathrm{OH}$ group as an intramolecular proton shuttle in a 6-member cycle and its energy is much lower $\left(15.3 \mathrm{kcal} \mathrm{mol}^{-1}\right)$ because it does not have the same 5 -membered ring constraint as TS1.

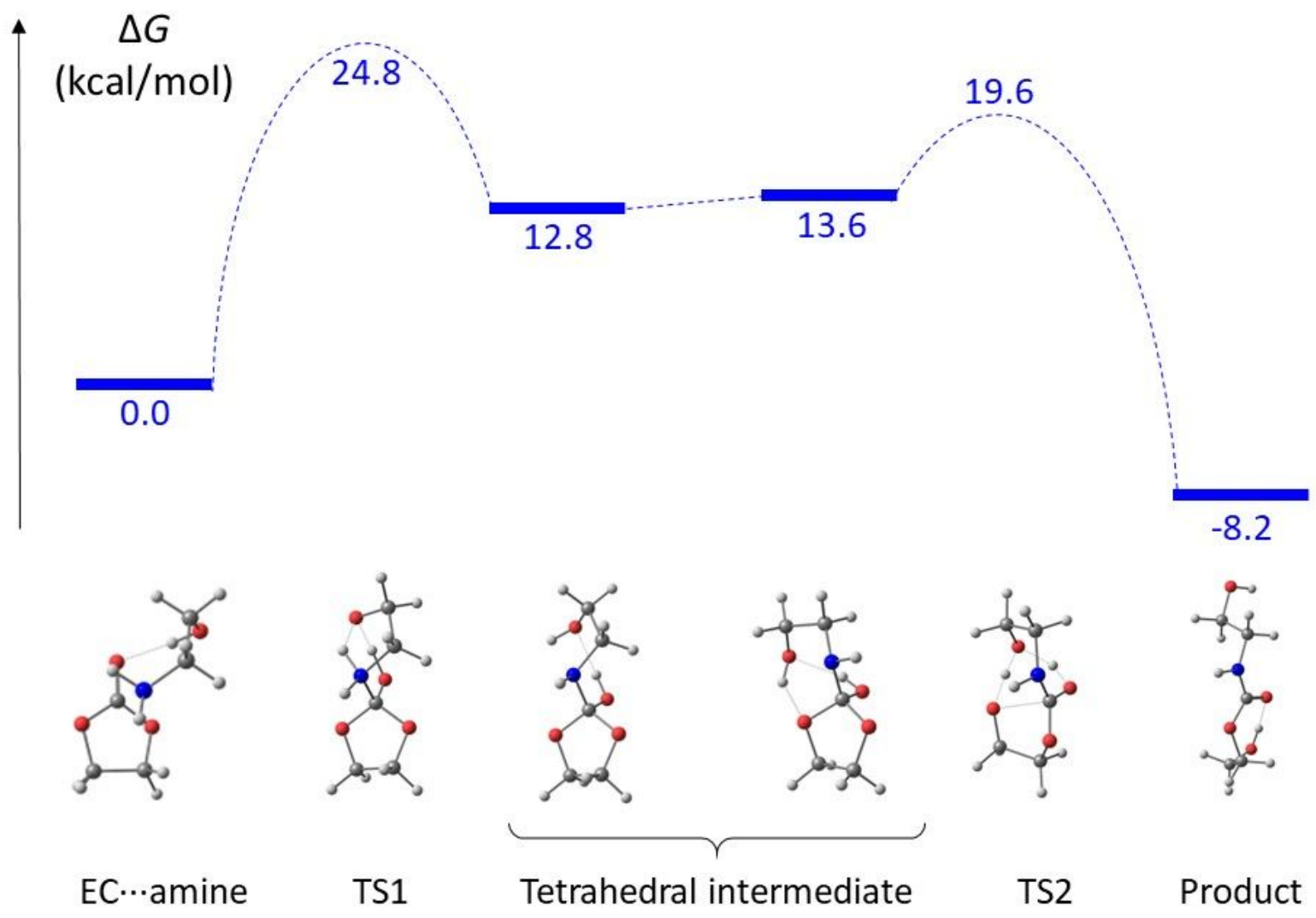

Figure 5: Free-energy profile for the single-amine-molecule pathway of the ethylene carbonate aminolysis with $\mathrm{HOCH}_{2} \mathrm{CH}_{2} \mathrm{NH}_{2}$.

The barrier difference between the one-molecule pathway (Figure 5, $24.8 \mathrm{kcal} \mathrm{mol}^{-1}$ ) and the twomolecule pathway (Figure 4, $11.4 \mathrm{kcal} \mathrm{mol}^{-1}$ ) appears too large when considering that both pathways are competitive. In the real system, this difference may be attenuated by specific stabilizing effects by solvent molecules. In conclusion, the DFT analysis of the single-hydroxylamine pathway, though only qualitative and limited to the stepwise mechanism, indicates that the reaction channel with the firstorder dependence on the amine concentration, in a solvent that cannot participate directly as a proton shuttle in the proton transfer chain, is made possible by the ability of the $\beta-\mathrm{OH}$ group to fulfil this role intramolecularly.

\section{Synthesis of monomers}

The PHU synthesis suffers from the low reactivity of five membered cyclic carbonates. Therefore, many studies described the use of catalysts or the optimization of the reaction parameters. ${ }^{23,24}$ For certain applications, where solvents and catalysts must be avoided, the monomer structure is the only 
available parameter to tune the aminolysis reactivity. The kinetic study has highlighted the difference of aminolysis reactivity between alkylamines and $\beta$-hydroxylamines. Moreover, $\beta$-hydroxylamines can easily be synthesized from biobased epoxy compounds. Therefore, we focused on the synthesis of polyfunctional $\beta$-hydroxylamine and polyfunctional cyclic carbonate monomers in order to synthesize $100 \%$ biobased PHU thermosets. To this end, two polyfunctional cyclic carbonates and a trifunctional $\beta$-hydroxylamine monomer were synthesized (Figure ).

Trimethylolpropane tricarbonate (TMPTC) was accessed by condensation of trimethylolpropane triglycidyl ether (TMPTGE) and $\mathrm{CO}_{2}(20 \mathrm{bar})$ in ethyl acetate in the presence of tetrabutylammonium bromide (TBAB) as catalyst. Full conversion after $72 \mathrm{~h}$ of reaction was confirmed by ${ }^{1} \mathrm{H}$ NMR (Figure S4). On the other hand, aminolysis of TMPTGE with $25 \%$ aqueous ammonia solution at $100{ }^{\circ} \mathrm{C}$ for $4 \mathrm{~h}$ yielded the trimethylolpropane tri- $\beta$-hydroxylamine (TMPT- $\beta-H A)$ equivalent. The epoxides were fully converted with a high $\beta$-hydroxylamine content ( $85 \%$ ) and around $15 \%$ of secondary amines according to approached quantitative ${ }^{13} \mathrm{C}$ NMR (Figure S7). Moreover, Pripol ${ }^{\mathrm{TM}} 1012$ from Croda, a biobased diacid derived from fatty acids, was reacted with glycerol carbonate in the presence of $N, N^{\prime}$ carbonyldiimidazole (CDI) in ethyl acetate at $25{ }^{\circ} \mathrm{C}$ for 3 days, producing Pripolm 1012 dicarbonate (Pripol- $\mathrm{C}_{5}$ ). The reaction was monitored by ${ }^{1} \mathrm{H}$ NMR and stopped once the full conversion of the acid functions was achieved (Figure S5). To compare two similar thermoset networks, Priamine ${ }^{\mathrm{TM}} 1071$ (Figure S8), a biobased diamine derived from fatty acids, was selected for its similar structure with the Pripol $^{\mathrm{TM}} 1012$. 

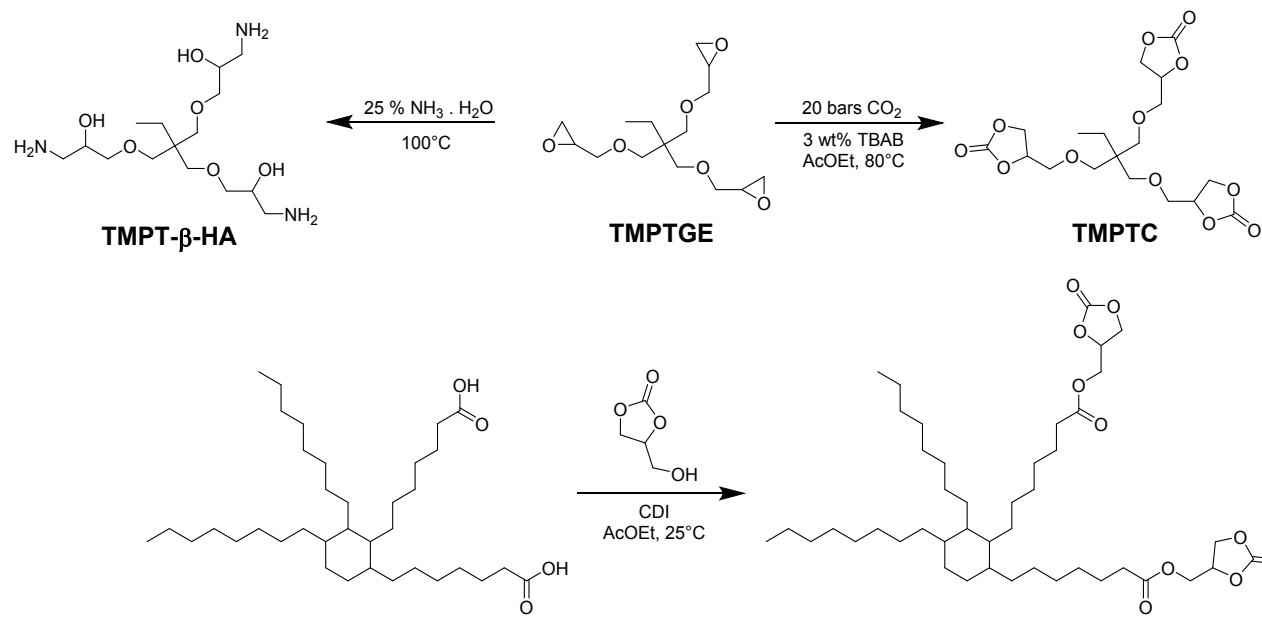

Pripol ${ }^{\mathrm{TM}} 1012$

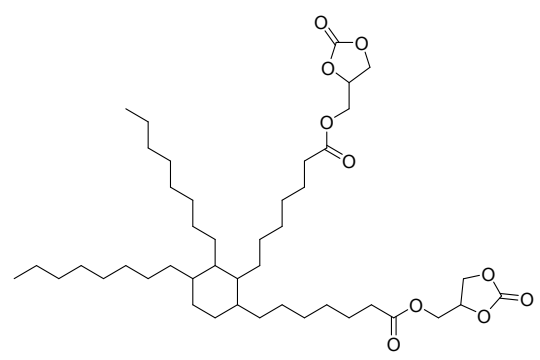

Pripol- $\mathrm{C}_{5}$

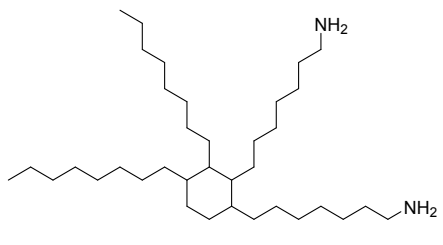

Priamine $^{\mathrm{TM}} 1071$

Figure 6: Monomer structures with their synthetic pathways. Pripol ${ }^{\mathrm{TM}} 1012$ and Priamine ${ }^{\mathrm{TM}} 1071$ representations are ideal structures.

\section{PHU thermosets}

\section{Rheological experiments}

Since the higher reactivity of $\beta$-hydroxylamines compared to alkyl amines for the aminolysis of cyclic carbonates was demonstrated by the model reactions on EC, the next step was to highlight this reactivity difference in the synthesis of $100 \%$ biobased PHU thermosets. In order to compare two structurally similar networks, two simple formulations were defined with the four monomers presented in the previous section. The first one consisted of a TMPTC and Priamine ${ }^{\mathrm{TM}} 1071$ formulation (PHU1), while the second one was composed of TMPT- $\beta$-HA and Pripol- $\mathrm{C}_{5}$ (PHU2). In both formulations, the cyclic carbonate/amine ratio was 1:1. Therefore, both thermoset networks will contain similar aliphatic backbone from Priamine ${ }^{\mathrm{TM}} 1071$ and Pripol ${ }^{\mathrm{TM}} 1012$ and trimethylolpropane backbones. However, TMPT- $\beta$-HA/Pripol- $C_{5}$ material would present supplementary ester functions and hydroxyl groups coming from the $\beta$-hydroxylamines. Those two functions may increase the hydrogen bond density in the material and could improve its mechanical properties.

The pot life and gelation time of the two formulations were measured by oscillatory rheology. Indeed, the pot life corresponds to the time during which the mixture viscosity remains low enough to allow its processing by casting. Typically, the pot life is determined as the time needed for the mixture to reach a viscosity of 10 Pa.s. On the other hand, the gelation time is the time required for the gelation 
of the polymer system, resulting from the aminolysis crosslinking. Since the gelation time is representative of the network formation rate, it depends on the monomer functionality. Indeed, the more the monomer functionality increases, the more the gelation time decreases, as the polymer network is achieved at a lower function conversion. Therefore, thanks to the similar structure and functionality of our monomers and formulations, the gelation times of both PHU1 and PHU2 are representative of their reactivity. Typically, the gelation time is determined as the time at which the storage modulus $\left(G^{\prime}\right)$ and loss modulus $\left(G^{\prime \prime}\right)$ crossover takes place. The oscillatory rheological experiments were performed with plate-plate geometry at $80^{\circ} \mathrm{C}$ at $1 \mathrm{~Hz}$ and an applied stress of $10 \mathrm{~Pa}$ (Figure 7), according to the determined linear domain. Pot life and gelation times of both PHU1 and PHU2 are given in Error! Reference source not found..

PHU1 achieved the gelation point after $5 \mathrm{~h} 22$ with a pot life of $3 \mathrm{~h}$ 05, whereas PHU2 crosslinking was quicker with a gelation time of $1 \mathrm{~h} 04$ and a pot life of 50 min. Conversely, in 2016 Blattmann et al. ${ }^{31}$ reported prolonged gelation times with the increase of $\beta$-hydroxylamine ratio in their formulations, probably because they were using very viscous, highly functional $\beta$-hydroxylamines, which entailed a lack of reactive function mobility. Therefore, the crosslinking rate was most likely governed by the mixture physical parameters than the chemical kinetic itself. Hence, gelation times measured was not necessarily representative of the function reactivity. In our case, the use of $\beta$-hydroxylamine (TMPT- $\beta$ HA) strongly increased the crosslinking aminolysis in comparison to alkylamine (Priamine ${ }^{\mathrm{TM}} 1071$ ) in agreements with our previous kinetic study.

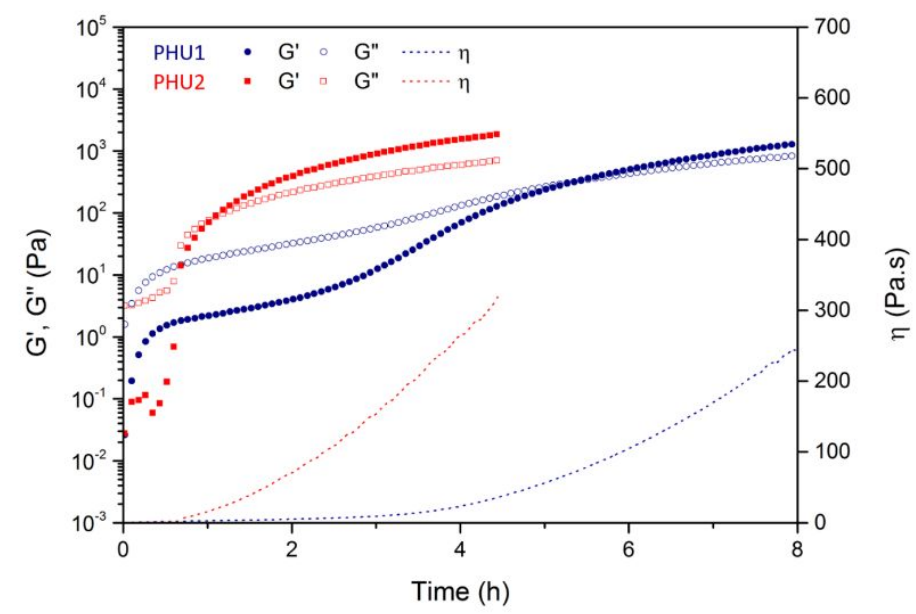

Figure 7: Rheological experiments for determination of gelation and pot life time at $80^{\circ} \mathrm{C}$ for PHU1 and PHU2 at $1 \mathrm{~Hz}$ and $10 \mathrm{~Pa}$ of stress. 
Table 3: Formulation, pot life and gelation time of PHU1 and PHU2.

\begin{tabular}{|c|c|c|c|c|c|}
\hline \multicolumn{2}{|c|}{ Cyclic carbonate } & \multicolumn{2}{|c|}{ Amine } & & \\
\hline TMPTC & Pripol- $C_{5}$ & TMPT- $\beta-H A$ & Priamine $^{\mathrm{TM}} 1071$ & Pot life & Gelation time \\
\hline 100 & - & - & 100 & $3 \mathrm{~h} 05$ & 5 h 22 \\
\hline - & 100 & 100 & - & $50 \mathrm{~min}$ & 1 h 04 \\
\hline
\end{tabular}

\section{Thermoset synthesis}

To obtain PHU thermosets, both formulations PHU1 and PHU2 were prepared and cured at $80{ }^{\circ} \mathrm{C}$ for $10 \mathrm{~h}$, and $6 \mathrm{~h}$ at $120^{\circ} \mathrm{C}$, then post-cured $1 \mathrm{~h}$ at $150{ }^{\circ} \mathrm{C}$. The conversion of cyclic carbonates into polyhydroxyurethanes was confirmed by IR spectroscopy with the appearance of the urethane bands at $1787 \mathrm{~cm}^{-1}$ and $1797 \mathrm{~cm}^{-1}$, for PHU1 and PHU2 respectively (Figure S9). Moreover, PHU2 exhibited the supplementary ester band at $1726 \mathrm{~cm}^{-1}$ from Pripol- $\mathrm{C}_{5}$ (Figure S10). Furthermore, both thermosets had a high gel content of $94 \%$ and $96 \%$ for PHU1 and PHU2 respectively, which confirmed an efficient crosslinking.

\section{Thermo-mechanical properties}

Both PHU1 and PHU2 were first analyzed by DSC to determine their $\mathrm{T}_{\mathrm{g}}$ (Figure S11), yielding the results summarized in Table 4. As expected, very close $\mathrm{T}_{\mathrm{g}}$ values were obtained, $-5^{\circ} \mathrm{C}$ and $-7{ }^{\circ} \mathrm{C}$ for PHU1 and PHU2 respectively. The close values of crosslinking density $\left(v^{\prime}\right)$ and swelling capacity of the two materials also confirmed their similar networks. The thermo-mechanical properties were then studied by DMA. The storage modulus $E^{\prime}$ and $\tan \delta$ variations with the temperature are shown in Figure. Once again, the properties of the two materials are comparable, with $\mathrm{E}_{\text {glassy }}$ of $1.28 \mathrm{GPa}$ and $1.44 \mathrm{GPa}$ for PHU1 and PHU2, respectively, and $\mathrm{E}_{\text {rubbery }}^{\prime}$ of $0.6 \mathrm{MPa}$ for both. Moreover, the alpha-transition temperature $\left(T_{\alpha}\right)$ was measured by the maximum of $\tan \delta$ of each material. Interestingly, PHU2 presented two $\mathrm{T}_{\alpha}$ at $2{ }^{\circ} \mathrm{C}$ and $22{ }^{\circ} \mathrm{C}$, while PHU1 had a single one at $10^{\circ} \mathrm{C}$. Nevertheless, the mean $\mathrm{T}_{\alpha}$ of PHU2 is $12{ }^{\circ} \mathrm{C}$, therefore the similarity of $\mathrm{T}_{\alpha}$ between PHU1 and PHU2 is comparable to $\mathrm{T}_{\mathrm{g}}$ measured by DSC. However, the presence of two $T_{\alpha}$ could indicate a network heterogeneity. Indeed, with the presence of ester functions from Pripol- $C_{5}$ and additional hydroxyl groups from $\beta$-hydroxylamines, the PHU2 network may arrange itself through hard segments composed of hydroxyurethane, ester and hydroxyl functions $\left(T_{\alpha}=22^{\circ} \mathrm{C}\right)$, and softer segments composed of the large aliphatic chains of Pripol$\mathrm{C}_{5}\left(\mathrm{~T}_{\alpha}=2{ }^{\circ} \mathrm{C}\right)$. The use of $\beta$-hydroxylamines and alkylamines led to similar thermo-mechanical properties. Nevertheless, the DMA analyses highlighted a $T_{\alpha}$ difference between the two thermosets resulting from a different network arrangement of PHU2 induced by ester and additional hydroxyl functions. 

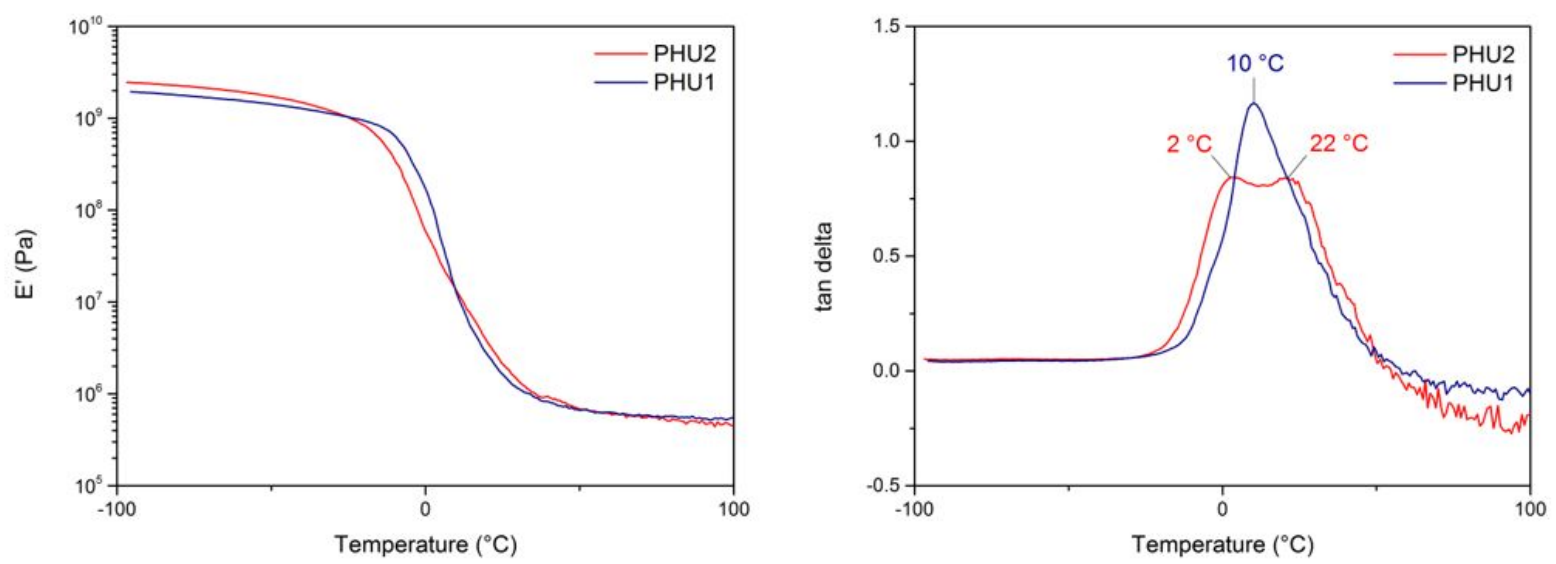

Figure 8: DMA measurements of PHU thermosets (right: storage modulus (E'); left: $\tan \delta$ ).

Table 4: Physico-chemical properties of PHU thermosets.

\begin{tabular}{|c|c|c|c|c|c|c|c|c|c|}
\hline PHU & $\begin{array}{l}T_{d 5 \%} \\
\left({ }^{\circ} \mathrm{C}\right)\end{array}$ & $\begin{array}{l}\text { Char } \\
\text { (\%) }\end{array}$ & $\begin{array}{c}T_{g} \\
\left({ }^{\circ} \mathrm{C}\right)\end{array}$ & $\begin{array}{l}\mathrm{T}_{\alpha} \\
\left({ }^{\circ} \mathrm{C}\right)\end{array}$ & $\begin{array}{l}E_{\text {glassy }}^{\prime} \\
\text { (Gpa) }\end{array}$ & $\begin{array}{l}E_{\text {rubbery }}^{\prime} \\
\text { (MPa) }\end{array}$ & $\begin{array}{c}v^{\prime} \\
\left(\mathrm{mol} / \mathrm{m}^{3}\right)\end{array}$ & $\begin{array}{l}\text { Swelling index } \\
\text { (\%) }\end{array}$ & $\begin{array}{c}\text { Gel content } \\
\text { (\%) }\end{array}$ \\
\hline 1 & 300 & 8 & -5 & 10 & 1.28 & 0.6 & 76 & 251 & 94 \\
\hline 2 & 246 & 10 & -7 & $2 / 22$ & 1.44 & 0.6 & 72 & 213 & 96 \\
\hline
\end{tabular}

\section{Thermal properties}

The thermal stability of the PHUs was explored by TGA from room temperature to $600{ }^{\circ} \mathrm{C}$ under a $\mathrm{N}_{2}$ atmosphere (Figure S12). PHU2 degraded at lower temperature $\left(T_{d 5 \%}=246^{\circ} \mathrm{C}\right)$ compared to PHU1 $\left(T_{d 5 \%}\right.$ $=300^{\circ} \mathrm{C}$ ). Indeed, ester functions are less resistant to temperature than hydroxyurethane linkages. Hence, the thermal stability of PHU2 was strongly reduced. However, the two thermosets had close char values, $8 \%$ and $10 \%$ for PHU1 and PHU2 respectively.

\section{Conclusion}

$\beta$-hydroxylamines are readily available from biobased epoxides by aminolysis with ammonia. Indeed, polyfunctional $\beta$-hydroxylamines are obtained through a one-step process without involving complex purifications. In addition to their eco-friendly synthesis, we have highlighted their higher reactivity toward cyclic carbonates compared to conventional alkylamines. Kinetic studies have revealed that butylamine exhibits a pure second order rate law for the $\mathrm{EC}$ aminolysis in $\mathrm{CDCl}_{3}$, whereas both first and second order pathways contribute to the aminolysis with 1-amino-2-butanol. Moreover, 1-amino-2butanol had a greater $k_{2}$ value of $5.6 \cdot 10^{-3} \mathrm{~L}^{2} \mathrm{~mol}^{-2} \mathrm{~s}^{-1}$ against $1.79 \cdot 10^{-3} \mathrm{~L}^{2} \mathrm{~mol}^{-2} \mathrm{~s}^{-1}$ for butylamine, which also justifies its higher reactivity. A DFT investigation highlighted the key role of the $\beta$-OH substituent in lowering the activation barrier through $\mathrm{H}$-bonding assistance relative to the alkylamine. The $\beta-\mathrm{OH}$ substituent is able to participate in the proton transfer chain both inter- and intramolecularly. 
Nevertheless, the single molecule pathway still represents a minor contribution relative to the twohydroxylamine pathway.

Furthermore, the higher $\beta$-hydroxylamine reactivity toward cyclic carbonates was confirmed for PHU thermoset synthesis by rheology. Indeed, the gelation time was reduced by a factor of five compared to alkylamine-based PHUs. Moreover, the two fully biobased PHU thermosets synthesized had very similar physico-chemical properties as expected from their complementary formulations. However, PHU2 presented a heterogeneous network with two $T_{\alpha}$ probably due to the ester linkages from Pripol$C_{5}$. These ester linkages also reduced the thermal stability of PHU2 compared to PHU1. $\beta$ hydroxylamines are very promising curing agents combining a green synthesis pathway and a higher reactivity toward epoxides and cyclic carbonates.

\section{Author information}

\section{Co-corresponding authors}

*E-mail address: rinaldo.poli@lcc-toulouse.fr (R. Poli); sylvain.caillol@enscm.fr (S. Caillol)

\section{Notes}

The authors declare no competing financial interest

\section{References}

1 D. Randall and S. Lee, The Polyurethanes Book, Wiley, 2003.

2 A. Tenorio-alfonso, M. C. Sánchez and J. M. Franco, J. Polym. Environ., , DOI:10.1007/s10924020-01659-1.

3 B. Eling, Ž. Tomović and V. Schädler, Macromol. Chem. Phys., 2020, 221, 1-11.

4 D. P. Pfister, Y. Xia and R. C. Larock, ChemSusChem, 2011, 4, 703-717.

5 I. Singh, S. K. Samal, S. Mohanty and S. K. Nayak, Eur. J. Lipid Sci. Technol., 2020, 122, 1-23.

6 D. Bello, S. R. Woskie, R. P. Streicher, Y. Liu, M. H. Stowe, E. A. Eisen, M. J. Ellenbecker, J. Sparer, F. Youngs, M. R. Cullen and C. A. Redlich, Am. J. Ind. Med., 2004, 46, 480-491.

7 D. Bello, C. A. Herrick, T. J. Smith, S. R. Woskie, R. P. Streicher, M. R. Cullen, Y. Liu and C. A. Redlich, Environ. Health Perspect., 2007, 115, 328-335.

8 M. S. Kathalewar, P. B. Joshi, A. S. Sabnis and V. C. Malshe, RSC Adv., 2013, 3, 4110-4129.

9 L. Maisonneuve, O. Lamarzelle, E. Rix, E. Grau and H. Cramail, Chem. Rev., 2015, 115, 1240712439.

10 G. Rokicki, P. G. Parzuchowski and M. Mazurek, Polym. Adv. Technol., 2015, 26, 707-761.

11 B. Nohra, L. Candy, J. F. Blanco, C. Guerin, Y. Raoul and Z. Mouloungui, Macromolecules, 2013, 46, 3771-3792.

12 C. Carré, Y. Ecochard, S. Caillol and L. Avérous, ChemSusChem, 2019, 12, 3410-3430.

13 A. Llevot and M. Meier, Polym. Int., 2019, 68, 826-831. 
Y. Ecochard and S. Caillol, Eur. Polym. J., 2020, 137, 109915.

H. Blattmann, M. Fleischer, M. Bähr and R. Mülhaupt, Macromol. Rapid Commun., 2014, 35, 1238-1254.

N. Yadav, F. Seidi, D. Crespy and V. D'Elia, ChemSusChem, 2019, 12, 724-754.

F. D. Bobbink, A. P. Van Muyden and P. J. Dyson, Chem. Commun., 2019, 55, 1360-1373.

H. Tomita, F. Sanda and T. Endo, J. Polym. Sci. Part A Polym. Chem., 2001, 39, 4091-4100.

Y. He, H. Keul and M. Möller, React. Funct. Polym., 2011, 71, 175-186.

H. Tomita, F. Sanda and T. Endo, J. Polym. Sci. Part A Polym. Chem., 2001, 39, 860-867.

H. Tomita, F. Sanda and T. Endo, J. Polym. Sci. Part A Polym. Chem., 2001, 39, 162-168.

M. Blain, L. Jean-Gérard, R. Auvergne, D. Benazet, S. Caillol and B. Andrioletti, Green Chem., $2014,16,4286-4291$.

A. Cornille, R. Auvergne, O. Figovsky, B. Boutevin and S. Caillol, Eur. Polym. J., 2017, 87, 535552.

M. V. Zabalov, M. A. Levina and R. P. Tiger, Russ. J. Phys. Chem. B, 2019, 13, 778-788.

A. Cornille, M. Blain, R. Auvergne, B. Andrioletti, B. Boutevin and S. Caillol, Polym. Chem., 2017, 8, 592-604.

C. D. Diakoumakos and D. L. Kotzev, Macromol. Symp., 2004, 216, 37-46.

F. Camara, S. Benyahya, V. Besse, G. Boutevin, R. Auvergne, B. Boutevin and S. Caillol, Eur. Polym. J., 2014, 55, 17-26.

A. S. Mora, R. Tayouo, B. Boutevin, G. David and S. Caillol, Green Chem., 2018, 20, 4075-4084.

X. Xu, R. Wang, L. Ling and J. O. Burgess, J. Polym. Sci. Part A Polym. Chem., 2007, 45, 99-110.

Y. Kaburagi and Y. Kishi, Tetrahedron Lett., 2007, 48, 8967-8971.

H. Blattmann and R. Mülhaupt, Green Chem., 2016, 18, 2406-2415.

D. J. Frisch, M. J.; Trucks, G. W.; Schlegel, H. B.; Scuseria, G. E.; Robb, M. A.; Cheeseman, J. R.; Scalmani, G.; Barone, V.; Mennucci, B.; Petersson, G. A.; Nakatsuji, H.; Caricato, M.; Li, X.; Hratchian, H. P.; Izmaylov, A. F.; Bloino, J.; Zheng, G.; Sonnenb, 2009.

S. Grimme, J. Antony, S. Ehrlich and H. Krieg, J. Chem. Phys., 2010, 132, 154104.

A. V. Marenich, C. J. Cramer and D. G. Truhlar, J. Phys. Chem. B, 2009, 113, 6378-6396.

V. S. Bryantsev, M. S. Diallo and W. A. Goddard III, J. Phys. Chem. B, 2008, 112, 9709-9719.

M. A. Levina, V. G. Krasheninnikov, M. V. Zabalov and R. P. Tiger, Polym. Sci. - Ser. B, 2014, 56, 139-147.

M. A. Levina, M. V. Zabalov, V. G. Krasheninnikov and R. P. Tiger, React. Kinet. Mech. Catal., 2020, 129, 65-83.

M. V. Zabalov and R. P. Tiger, Theor. Chem. Acc., 2017, 136, 95. 